\title{
Analysis Electricity System at Wind Power Plan (PLTB) Vertical
}

\author{
M M Isa ${ }^{1}$, D Syahbana 2 , A Pramana ${ }^{3}$, R Andika ${ }^{4}$, P Wulandari ${ }^{5}$, A Syahriar $^{6}$ \\ \{Musawirmuhamad@gmail.com¹, Syahbanad@gmail.com² ${ }^{2}$ Ivanadhi96jkt@gmail.com ${ }^{3}$, \\ Rhezaandhika@rocketmail.com ${ }^{4}$,putri.wulandari@uai.ac.id ${ }^{5}$, ary@uai.ac.id ${ }^{6}$ \\ Electrical Engineer, Faculty of Science and Technology, Universitas Al Azhar Indonesia, Komplek \\ Masjid Agung Al Azhar, Jalan Sisingamangaraja, Kebayoran Baru, Jakarta Selatan 12110
}

\begin{abstract}
The crisis of energy teaches us, the Indonesian people, about serious and complicated efforts to develop and implement renewable energy sources to save related to fossil fuels that need to be done immediately. Therefore, to minimize the use of fossil fuels, the government has begun to look for alternative energy, one of which is air, sun and wind. Basically, the energy source will never run out. Wind power plant (PLTB) is a power plant that uses energy to rotate turbines in the general so that it produces electricity. In this study the results can be known by using several types of wind, namely small, medium and large. Where the wind speed ranges from 3.4-5.2 m / s (Small), 5.3-7.4 m/ s (Medium) and 7.5-9.8 m/ s (Large). Simulation then uses 3 types of wind and has several results which are equal to $0.817 \mathrm{~V}$ with a small wind speed, $1.246 \mathrm{~V}$ with moderate wind speeds and $1.796 \mathrm{~V}$ with large wind speeds.
\end{abstract}

Keywords: Wind Power, Energy, Turbines, Power Plant

\section{Introduction}

The development of a renewable energy can optimize work from a use because renewable energy is energy that can be renewed continuously or easily obtained. Renewable energy can also replace energy that is difficult to obtain, especially oil derived from fossils of living things in thousands to millions of years ago. Along with the increasing energy needs due to the increasing population in the world, there needs to be a breakthrough to replace the non-renewable energy. One of them is the use of wind. Wind is air that moves from a high-pressure area to a low pressure[1]

Wind is a renewable energy that can be used directly by humans. For example, the wind on the toll road (freeway), the wind on the toll road can be utilized because it has a speed of 4-6 m/ sec. This wind turbine aims to be a power plant for street lighting especially toll roads, many toll roads require street lighting, now there are many traffic lights that use alternative energy using solar energy or better known as solar power sell. Solar power is a cheap and economical alternative to be used as a lighting source because it uses free and unlimited energy sources from nature. Research in this field continues and there are several technical problems, one of which is the wind speed and spacing of the blade in the turbine which affects the performance of Savonius vertical shaft wind turbines[2]

The development of wind energy in Indonesia is currently still relatively low. One reason is because the average wind speed in Indonesia is classified as low wind speed, which ranges from 3 $\mathrm{m} / \mathrm{s}$ to $5 \mathrm{~m} / \mathrm{s}$, making it difficult to produce electricity on a large scale. Nonetheless, the wind potential in Indonesia is available most of the year, making it possible to develop a small-scale power generation system. One form of windmill that is relatively easy to make is a windmill with a vertical 
axis. This type of windmill rotates by utilizing wind speed from sharing direction and easily converted to generate electrical energy[3]

\section{Literature Review}

Electric current is the amount of electric charge caused by the movement of electrons, flowing through a point in an electric circuit each unit of time. Electric current can be measured in units of Coulomb / second or Ampere. In most direct current circuits, it can be assumed that resistance to an electric current is constant so that the amount of current flowing in the circuit depends on voltage and resistance according to Ohm's law. To find an electric current can be found by the formula:

$$
\mathrm{I}=\frac{\mathrm{V}}{\mathrm{R}}
$$

$$
\begin{aligned}
& \mathrm{I}=\text { Electric Current }(\mathrm{A}) \\
& V=\text { Voltage (Volt) } \\
& \mathrm{R}=\text { Resistance (ohms) }
\end{aligned}
$$

Electrical voltage is the difference in electrical potential between two points in an electrical circuit, and is expressed in volts. This magnitude measures the potential energy of an electric field which results in electricity flowing in an electrical conductor. Depending on the difference in electric potential, an electric voltage can be said to be extra low, low, high or extra high.[4] By definition electricity voltage causes negative electrically charged objects to be pulled from low voltage places to high places. To find the voltage can be known by:

$$
V=\mathrm{I} \times R
$$

A generator is a voltage source that is obtained by changing mechanical energy into electrical energy. The generator works based on the principle of electromagnetic induction[5], that is by rotating a coil in a magnetic field so that an induced emf emerges. The generator has two main components, namely the stationary part (stator) and the moving part (rotor). The rotor is connected to the generator shaft which rotates at the centre of the stator. The generator shaft is usually rotated 
using an external effort that can come from a turbine, either a water turbine or a steam turbine and then processes produce electricity[3].

Alternator is an electromechanical device that converts mechanical energy into electrical energy alternating current. In principle, alternating current electric generators are called alternators, but the generally accepted understanding is the electric generator on a vehicle engine.[6] The alternator in the power plant which is driven by a steam turbine is called the turbo alternator.

\section{Research Methodology}

The following is a flow diagram of research activities on Wind Power Plants (PLTB)

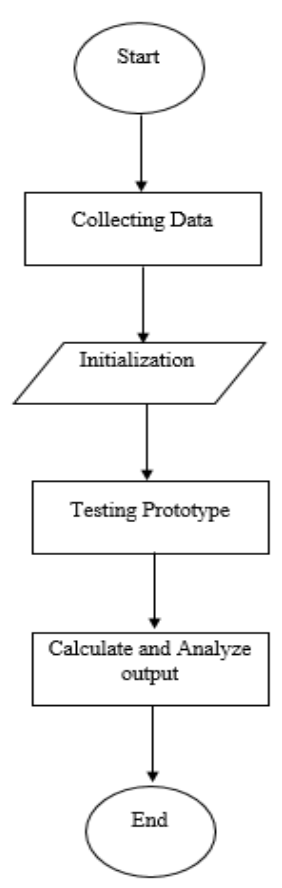

Figure 1. Methodology of this research

In the Figure 1. shows this research conducted to trials of this research by searching for data, testing tools and calculating and calculating tools while operating

\section{Results and Discussion}


The working principle of this tool is to rotate the generator with the help of a turbine which is driven by wind from the vehicle on the freeway and the tool is placed right in the middle of the freeway area, with the right propeller design then the turbine can move with the two-way wind aid generated by four-wheeled vehicles.

The generator applies the faraday legal principle in which magnetic fields produce electric currents, and also we use small toothed teeth and small diameters to be installed on a generator and large-diameter gears to be installed on a turbine. electricity[7].

The simulation results of Wind Power Plant (PLTB) testing against the determined wind. As a prototype, we use a mini dc generator that does not require high rotational speed to be able to generate electricity and turn on the LEDs in the circuit, at $2200 \mathrm{Rpm}$ the generator can produce 80 VDC, but to reach $2200 \mathrm{Rpm}$ the prototype is quite difficult because there are some obstacles, and also our target for this prototype is to be able to turn on a LED that only requires $3 \mathrm{~V}$ voltage, around 120-240 Rpm generator can turn on 3V LEDs with the help of aeromodelling propellers, the electricity generated by the generator will be channelled first through the stabilizer circuit and charging circuit/battery discharging for power storage, then channelled to the load, so that the electric current is not wasted and can be saved to power or battery storage and can also use batteries, the results of the prototype are quite satisfactory and can be applied to make real tools with more mature and detailed calculations selection of suitable material, the desired tool can be made very efficiently[8].

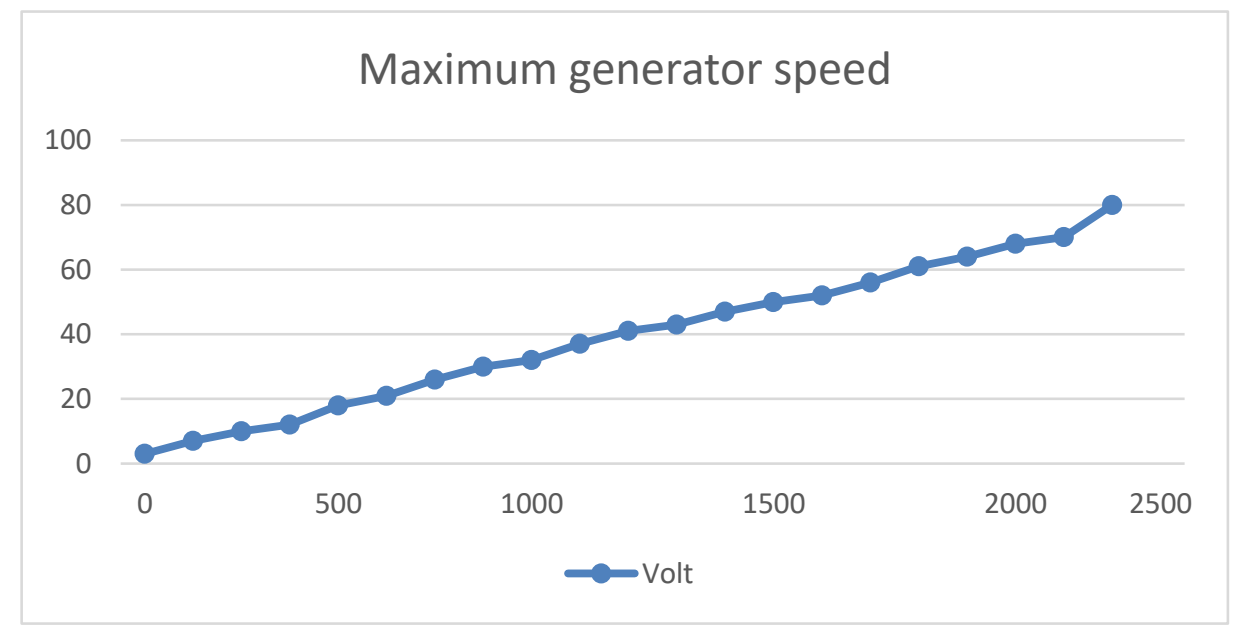

Figure 2.Graph voltage at maximum speed generator

In Figure 2 shows a graph of the increase in voltage where the greater the wind, the greater the voltage. This data is taken using a variety of speeds so as to produce maximum speed 


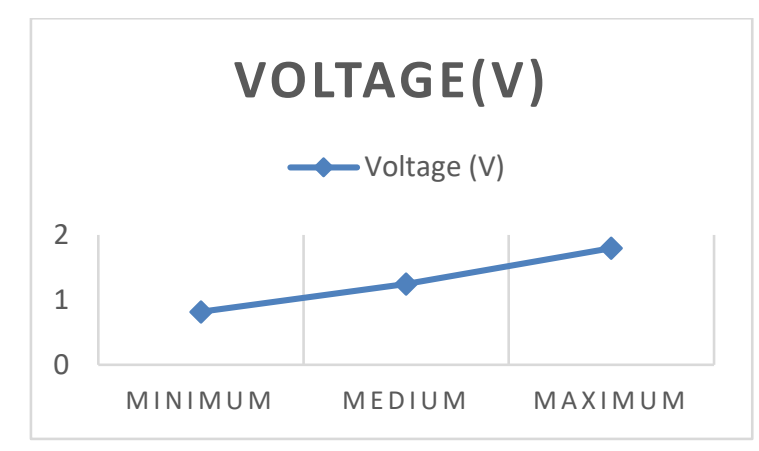

Figure 3. Graphs of stress on the results of trials using several wind scales

In Figure 3 shows that the greater the wind is obtained, the greater the voltage obtained. And it can be concluded that the distance of each significant wind condition will produce a significant voltage

Table 1. Simulation of stresses obtained at several wind speeds

\begin{tabular}{cc}
\hline Wind Velocity & Voltage found $(\mathrm{V})$ \\
\hline Small $(3,4-5,2) \mathrm{m} / \mathrm{s}$ & 0,817 \\
Medium $(5,3-7,4) \mathrm{m} / \mathrm{s}$ & 1,246 \\
Large $(7,5-9,8) \mathrm{m} / \mathrm{s}$ & 1,796 \\
\hline
\end{tabular}

Table 1 shows, the simulation results with speed variations, each of each voltage value that determines the speed value produced. The speed effect is the higher the speed, the greater the value of the voltage produced.

\section{Conclusion}

Each Based on the results of the simulation above it can be concluded that the Wind Power Plant (PLTB) produces an output voltage when testing without load with a small wind speed of 0.817 volts. With a medium wind speed of 1.246 volts and with a large speed get a result of 1.796 . Variation in load and the speed at the generator will affect the output value of the generator voltage, current and output power. The higher the speed and load, the higher the value of current, voltage and torque and is directly proportional to the value of the load. The efficiency value is obtained from the deduction between the output power and the input power value multiplied by 100 percent. In this study we have a problem with the lack of inadequate sources of raw materials. Because of this, the generator that we use, the shaft rotation in the generator is less efficient and has a large gap from the rotation of the rotor in the generator.

of the text. 


\section{References}

[1] S. R. Shah, R. Kumar, K. Raahemifar, and A. S. Fung, "Design, modeling and economic performance of a vertical axis wind turbine," Energy Reports, vol. 4, pp. 619-623, 2018, doi: 10.1016/j.egyr.2018.09.007.

[2] P. S. Y. Sayais, G. P. Salunkhe, P. G. Patil, and M. F. Khatik, "Power Generation on Highway by using Vertical Axis Wind Turbine \& Solar System," Int. Res. J. Highw. by Using Vert. Axis Wind Turbine Sol. Syst., vol. 05, no. 03, pp. 2133-2137, 2018.

[3] C. saleh Yusuf Ismail Nahkoda, Design of Vertical Axis Windmills Portable Power Plant, Electrical. Malang: National Institute of Technology Malang, 2018.

[4] Syamsul Bahari, "Analisis Pembangkit Listrik Tenaga Angin Di Desa Sungai Nibung Kecamatan Teluk Pakedai Kabupaten Kubu Raya,” Anal. Pembangkit List. Tenaga Angin Di Desa Sungai Nibung Kec. Teluk Pakedai Kabupaten Kubu Raya, 2015.

[5] M. Ooshima, A. Chiba, T. Fukao, and M. Azizur Rahman, "Design and analysis of permanent magnet-type bearingless motors," IEEE Trans. Ind. Electron., 1996, doi: 10.1109/41.491353.

[6] B. F. Ibrahim Nawawi, "Small-scale wind power generation systems," vol. Magelang:T, 2009.

[7] H. M. p. Eko sulistiyo M.T., Wind power plants use vertical axis. Bangka Belitung: Bangka Belitung Manufacturing Polytechnic., 2015.

[8] Putri Wulandari. 2018. DC generators and engines. Jakarta: Teaching Module for Electrical Machine Courses and Power systems, UAI. 